OPEN ACCESS

Edited by:

Emmanuel Pinteaux,

University of Manchester,

United Kingdom

Reviewed by:

Barry W. McColl,

University of Edinburgh

United Kingdom

Siddharth Krishnan,

University of Manchester,

United Kingdom

*Correspondence:

Rong Jin

riin@pennstatehealth.psu.edu

Guohong Li

guohongli@pennstatehealth.psu.edu

Specialty section

This article was submitted to

Stroke,

a section of the journal

Frontiers in Neurology

Received: 08 April 2019

Accepted: 23 July 2019

Published: 07 August 2019

Citation:

Jin R, Liu S, Wang M, Zhong W and

Li G (2019) Inhibition of CD147

Attenuates Stroke-Associated

Pneumonia Through Modulating Lung

Immune Response in Mice.

Front. Neurol. 10:853.

doi: 10.3389/fneur.2019.00853

\section{Inhibition of CD147 Attenuates Stroke-Associated Pneumonia Through Modulating Lung Immune Response in Mice}

\author{
Rong Jin*, Shan Liu, Min Wang, Wei Zhong and Guohong Li* \\ Department of Neurosurgery, The Pennsylvania State University College of Medicine, Hershey, PA, United States
}

Background and Purpose: Acute ischemic stroke triggers a profound systemic and local immunodysfunction that increased the susceptibility to infections, especially stroke-associated pneumonia (SAP). Our previous study has shown that inhibition of CD147 ameliorates acute ischemic stroke, however, the role of CD147 in post-stroke lung infection has not been investigated.

Methods: C57BL/6 mice were subjected to transient $(60 \mathrm{~min})$ middle cerebral artery occlusion, and treated with anti-CD147 antibody ( $\alpha$ CD147). Lung histological changes, vascular permeability, and pulmonary edema were determined. Bacterial burden in the lung tissue and Broncho alveolar lavage fluid (BALF) were measured. Lung leukocyte infiltration, circulating platelet-leukocyte aggregates, cell type-specific IL-17A, and IFN- $\gamma$ expression in the lung were detected by flow cytometry.

Results: CD147 expression was markedly upregulated in the lung after stroke. $\alpha$ CD147 treatment significantly decreased the stroke-associated lung histological damages, bacterial load, vascular permeability and pulmonary edema. The protective effects by $\alpha \mathrm{CD} 147$ treatment were associated with deceased lung inflammatory cell infiltration by reducing IL-17A expression in lung $\gamma \delta T$ cells and attenuated bacterial load by enhancing IFN- $\gamma$ expression in the lung NK1.1+ cells and CD4 ${ }^{+} \mathrm{T}$ cells. In addition, CD147 expression was also increased in the circulating platelets and leukocytes. Enhanced platelet-leukocyte aggregates following stroke was inhibited by $\alpha$ CD147 treatment.

Conclusions: Inhibition of CD147 ameliorates aberrant lung inflammatory and immune response and reduces bacterial infection after stroke. CD147 might represent a novel and promising therapeutic target for post-stroke lung infection.

Keywords: CD147, stroke, pneumonia, IL-17A, IFN- $\gamma$

\section{INTRODUCTION}

Acute ischemic stroke not only produces local brain damage but also triggers a profound systemic immune dysfunction, which results in approximately $30 \%$ of patients suffering from stroke-associated pneumonia (SAP) within the first few days after stroke (1-3). Experimental studies have shown that prophylactic antibiotic treatment and/or inhibition of increased sympathetic activity using the $\beta$-adrenergic receptor blocker propranolol are effective for 
preventing and treating SAP (4-6). However, the clinical relevance of these treatments remain uncertain. Two recent largescale clinical trials demonstrated that prophylactic antibiotic treatments did not reduce the incidence of mortality or SAP $(7,8)$. Moreover, beta-blocker therapy also did not reduce the risk for SAP, and had no direct effect on mortality at 7-days, even higher 30-days mortality (9). Thus, there is an urgent need to identify molecular signaling pathways that can be targeted with innovative therapies for SAP.

Cluster of differentiation 147 (CD147), a type I transmembrane glycoprotein of the immunoglobulin superfamily, is broadly expressed on different cell types, such as erythrocytes, leukocytes, platelets, endothelial cells and epithelial cells (10). Therapeutic targeting of CD147 has yielded encouraging results in experimental models of human diseases, such as rheumatoid arthritis, asthmatic lung inflammation, myocardial ischemia/reperfusion injury, autoimmune encephalomyelitis, and meningitis epidemics (1115). CD147 was also involved in immune synapse formation, $\mathrm{T}$ cells activation and Th17 cells differentiation by modulation of cytokine production (16-18). Our recent study has demonstrated that inhibition of CD147 ameliorates acute ischemic stroke in mice (19). However, the role of CD147 in stroke-associated lung immune response and pneumonia has not been investigated. Thus, the present study was designed to investigate the role of CD147 on the lung immune response and infection following acute ischemic stroke. We examined the therapeutic potential of blocking CD147 and its mechanism of action in prevention of SAP in mice after focal cerebral ischemia/reperfusion injury.

\section{MATERIALS AND METHODS}

Details of materials and experimental procedures are available in Supplemental Material. All animal experiments were approved by the Institutional Animal Care and Use Committee at Penn State University College of Medicine.

\section{Stroke Model and Antibody Treatment}

Mouse model of acute ischemic stroke was induced using transient $(60 \mathrm{~min})$ middle cerebral artery occlusion (MCAO) technique as we described previously $(19,20)$. Two hours after stroke, the mice were randomly assigned to the following treatment groups: a rat anti-mouse CD147 monoclonal antibody (1 mg/kg, Clone RL73.2, eBbioscience, named aCD147 mAb throughout this article) or isotype control antibody (rat IgG2a) administered via tail vein injection in $100 \mu \mathrm{L}$ volume of phosphate buffered saline (PBS, pH 7.4). For randomization, the web tool www.randomizer.org was used. The dose of $1 \mathrm{mg} / \mathrm{kg}$ per day for $\alpha$ CD147 was selected based on our previous studies (19). In the 24-h survival experiments, a single dose of antibody was given at $4 \mathrm{~h}$ after onset of ischemia. In the 72 -h survival experiments, antibody treatment was initiated at 4 or $8 \mathrm{~h}$, and repeated at 24 and $48 \mathrm{~h}$ after onset of ischemia. The number of animals used in each experimental group was summarized in Supplementary Table 1.

\section{Infarcts Volumes and Neurological Deficits}

Infarct volumes were measured in cresyl violet stained coronal sections on day 3 after MCAO, as previously described (20). The modified Bederson score (global neurological function) was performed by a blinded investigator (21).

\section{Lung Vascular Permeability and Water Content Assays}

Lung vascular permeability was evaluated by Evans Blue dye (EB) method as described previously (22). The water content was calculated as $=($ wet weight-dry weight $) /$ wet weight $\times 100 \%$.

\section{Bacteriological Analysis}

Mouse Bronchoalveolar lavage fluid (BALF) and lung tissues were collected. The number of cells and protein concentrations in the BALF were measured. Then, bacterial burden within the BALF and lung tissue homogenates were determined using brain-heart infusion (BHI) agar cultures as described previously $(20,23)$.

\section{Lung Histological and Immunohistochemical Assessment}

Lung sections were stained with $\mathrm{H} \& \mathrm{E}$ and graded on a scale from (1) normal, (2) focal ( $<50 \%$ lung section) interstitial congestion and inflammatory cell infiltration, (3) diffuse ( $>50 \%$ lung section) interstitial congestion and inflammatory cell infiltration, (4) focal ( $<50 \%$ lung section) consolidation and inflammatory cell infiltration, to (5) diffuse ( $>50 \%$ lung section) consolidation and inflammatory cell infiltration, as previously described (24). Immunohistochemistry was performed as described previously (19).

\section{Western Blot and Enzyme-Linked Immunosorbent Assays (ELISA)}

Mouse plasma and lung tissues were collected for analysis. The concentrations of IL-17A and IFN- $\gamma$ were measured using specific ELISA kits according to manufacturers' protocol. Western blotting were performed as described previously (19).

\section{Flow Cytometry}

Mouse blood and lung tissues were collected. The lung infiltrating cells were isolated with enzymatic digestion method as previously (25). Blood samples and isolated infiltrating cells were stained with antibody cocktails and run on a BD Accuri C6 Flow Cytometry. Data were analyzed by FlowJo software. The antibodies are listed as Supplementary Table 2.

\section{Quantitative Real-Time PCR}

Mouse lung tissues were collected. Total RNA was extracted by using the TRIzol extraction kit (Life Technologies). Expression levels of chemokines (CXCL1 and CXCL2) were determined by quantitative real-time RT-PCR with a Bio-Rad thermocycler and an SYBR green kit (Bio-Rad) according to the recommendations of the manufacturer. Mouse Gapdh was used as reference gene. The primers had the following sequences: CXCL1 forward $5^{\prime}$-TCGATGGTAGTTCAGTTCTGCT-3' and reverse $5^{\prime}$-TCG CACAACACCCTTCTACT-3', CXCL2 forward 5' -CCCTGCCA AGGGTTGACTTC- $3^{\prime}$ and reverse-5' - GGGGCTTCAGGGTCA 
AGG-3', Gapdh forward 5'-GCGAGATCCCGCTAACATCA-3', and reverse $5^{\prime}$-CTCGTGGTTCACACCCATCA- $3^{\prime}$. All samples were run in triplicate. Relative levels of mRNA were normalized to the mouse housekeeping gene, and the results are expressed as fold change vs. the sham controls.

\section{Statistical Analysis}

All results were expressed as mean \pm SD except for ordinal lung histopathologic scores and Bederson score that were depicted as scatter plots. Graphpad Prism 5 software package was used for statistical analysis. Unless otherwise indicated, multiple comparisons were made using a 1-way ANOVA followed by the Bonferroni post-hoc test. If only 2 groups were compared, unpaired, 2-tailed Student $t$-test was applied. Non-parametric lung histopathologic scores and Bederson scores were compared by Kruskal-Wallis test with post-hoc Dunn corrections. $P<0.05$ was considered statistically significant. All data were analyzed in a blinder manner.

\section{RESULTS}

\section{Inhibition of CD147 Attenuates Post-stroke Lung Damage}

Western blot analysis showed that CD147 protein expression in the lung tissue was elevated significantly at $24 \mathrm{~h}$, and continued to increase up to $72 \mathrm{~h}$ after stroke (The full images of western blot were available in Supplementary Figure 1) (Figure 1A). The unglycosylated CD147 has a molecular weight $27-29 \mathrm{kDa}$, whereas the glycosylated form has a molecular weight between 43 and $66 \mathrm{kDa}$ (26). This variance could be attributed to differential post-translational modification in different cell types. We detected multiple bands of CD147 protein in the lung tissue, suggesting that they might derive from different cell types in the lung after stroke. In addition, flow cytometry data showed that the CD147 expression was significantly increased in the isolated lung neutrophils and Ly6 $\mathrm{C}^{\mathrm{Hi}}$ monocytes/macrophages after stroke (Supplementary Figure 2).

$\alpha \mathrm{CD} 147$ treatment significantly decreased the development of post-stroke lung damage (Figure 1B). Histological examination revealed typical signs of bacterial pneumonia: lung consolidation, thickened alveolar septa and intra-alveolar inflammatory infiltrates in the isotype-treated mice at $24 \mathrm{~h}$ after stroke, and continued to development to $72 \mathrm{~h}$ (Figure 1B), as previously described (20). But no signs of pneumonia was found in the lung sections of sham mice (Figure 1B), indicating enhanced susceptibility to lung infection resulted from stroke but not from surgical stress. Moreover, the number of cells and levels of protein concentration in the BALF were significantly increased after stroke, but these increases were inhibited in $\alpha \mathrm{CD} 147$ treated mice compared with isotype control group (Figure 1C). Furthermore, microbiological analysis revealed significant bacterial loads in the BALF and lung tissue homogenate cultures of all mice $(n=12)$ at $24 \mathrm{~h}$ after stroke (Figure 1D). In contrast, sample cultures from sham-operated mice remained sterile (Figure 1D). Importantly, $\alpha \mathrm{CD} 147$ treatment profoundly reduced bacterial growth in the BALF (Figure 1D) and lung tissue cultures (Figure 1D) after stroke. In addition, no bacterial growth was observed in the blood cultures of either sham or MCAO mice (data not show), consistent with previous reports in C57Bl6 mouse strain $(20,27)$.

\section{Inhibition of CD147 Attenuates Post-stroke Lung Vascular Permeability and Edema Through Inhibition of MMP-9 Activity}

The lung vascular permeability was assessed by measuring extravasation of EB. The amount of extravasated EB dye (Figure 2A) within the lung tissue was significantly increased at $24 \mathrm{~h}$ after stroke compared with sham controls. However, it was reduced in the $\alpha \mathrm{CD} 147$-treated mice compared with isotypetreated mice (Figure 2A). Correspondingly, pulmonary edema was significantly reduced in $\alpha \mathrm{CD} 147$-treated mice compared with isotype-treated mice (Figure 2B). MMPs, in particular MMP-9, is involved in the pathogenesis of various pulmonary inflammatory diseases and associated with pulmonary edema (28). Western blot showed MMP-9 expression was significantly increased in the lung after stroke (The full images of western blot were available in Supplementary Figure 1) (Figure 2C), which was mainly derived from infiltrated neutrophils (Figure 2D) as determined by double immunostaining. Importantly, it was significantly abolished by $\alpha \mathrm{CD} 147$ treatment (Figures 2C,D).

\section{Inhibition of CD147 Modulates Changes in Leukocyte Subpopulations in the Lung After Stroke}

Leukocyte subpopulations in the lung tissues were analyzed by flow cytometry at $24 \mathrm{~h}$ after stroke. Figures $3 \mathrm{~A}-\mathrm{C}$ showed a gating strategy for identifying immune cell subpopulations in the lung, and representative flow cytometric dot plots in the indicated groups. The number of total leukocytes $\left(\mathrm{CD}_{4} 5^{+}\right)$, and the frequencies (Figure 3D) and absolute cell numbers (Figure 3E) of neutrophils $\left(\mathrm{CD} 45^{+} \mathrm{CD}_{11 b^{+}} \mathrm{Ly}_{6 \mathrm{G}}{ }^{+}\right), \mathrm{Ly}_{6} \mathrm{C}^{\mathrm{Hi}}$ monocytes $\left(\mathrm{CD}_{4} 5^{+} \mathrm{CD} 11 \mathrm{~b}^{+} \mathrm{Ly}_{6 \mathrm{G}}{ }^{-} \mathrm{Ly} 6 \mathrm{C}^{\mathrm{Hi}}\right)$, dendritic cells $\left(\mathrm{CD} 45^{+} \mathrm{CD} 11 \mathrm{c}^{\mathrm{Hi}} \mathrm{IA} / \mathrm{IE}^{\mathrm{Hi}}\right)$, and macrophages $\left(\mathrm{CD} 45^{+} \mathrm{CD} 11 \mathrm{c}^{\mathrm{Hi}}\right.$ $\mathrm{IA} / \mathrm{IE}^{\mathrm{Lo}}$ ) were significantly increased in the lungs of the isotypetreated group compared with sham controls, but these changes were attenuated in the $\alpha \mathrm{CD} 147$-treated group compared with the isotype-treated group (Figure 3D). Previous study showed that lung B cells play an important role in protecting against pneumonia via producing IgM (29). Interestingly, compared with sham mice, the frequency and absolute number of $\mathrm{B}$ cells in the lung were significantly decreased after stroke, but these decreases were significantly attenuated in $\alpha \mathrm{CD} 147$ treatment group (Figures 3D,E).

\section{Inhibition of CD147 Decreases Circulating Platelet-Leukocyte Aggregates After Stroke}

Enhanced platelet-leukocyte aggregates are a common mechanism for promoting leukocyte recruitment to the site of inflammation (30). Thus, we used flow cytometry to analyze CD147 expression and circulating plateletleukocyte aggregates in whole blood at $24 \mathrm{~h}$ after stroke. The expression of CD147 was markedly increased both in 
A

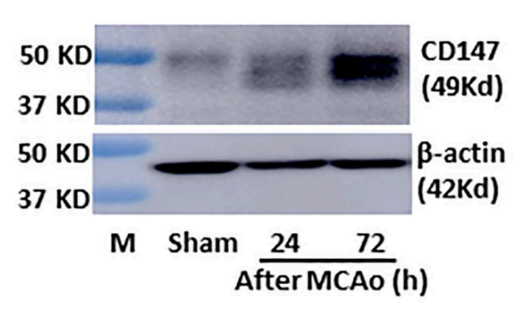

B

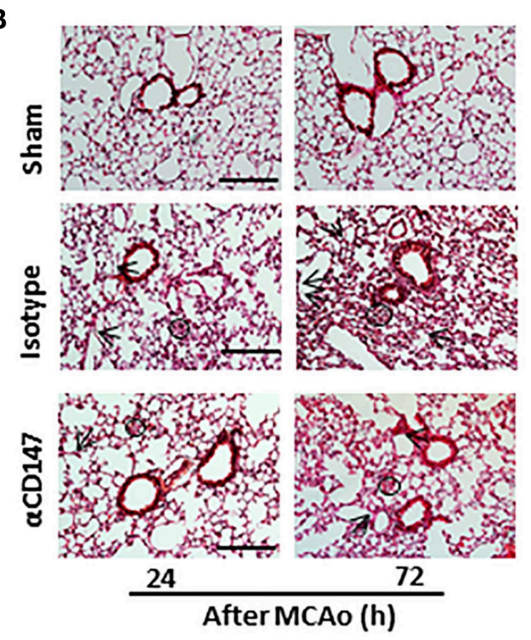

C

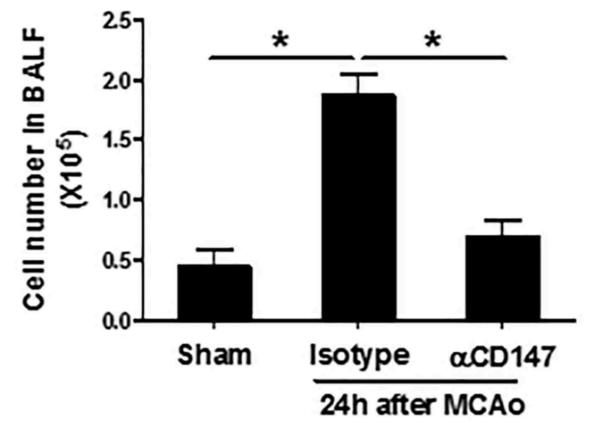

D

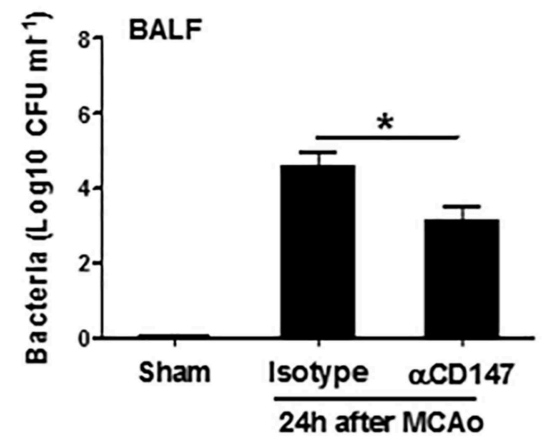

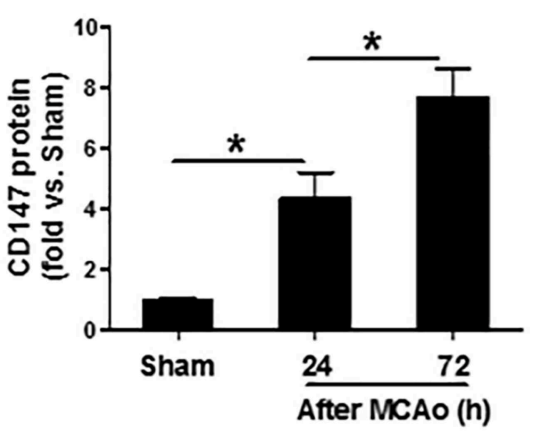
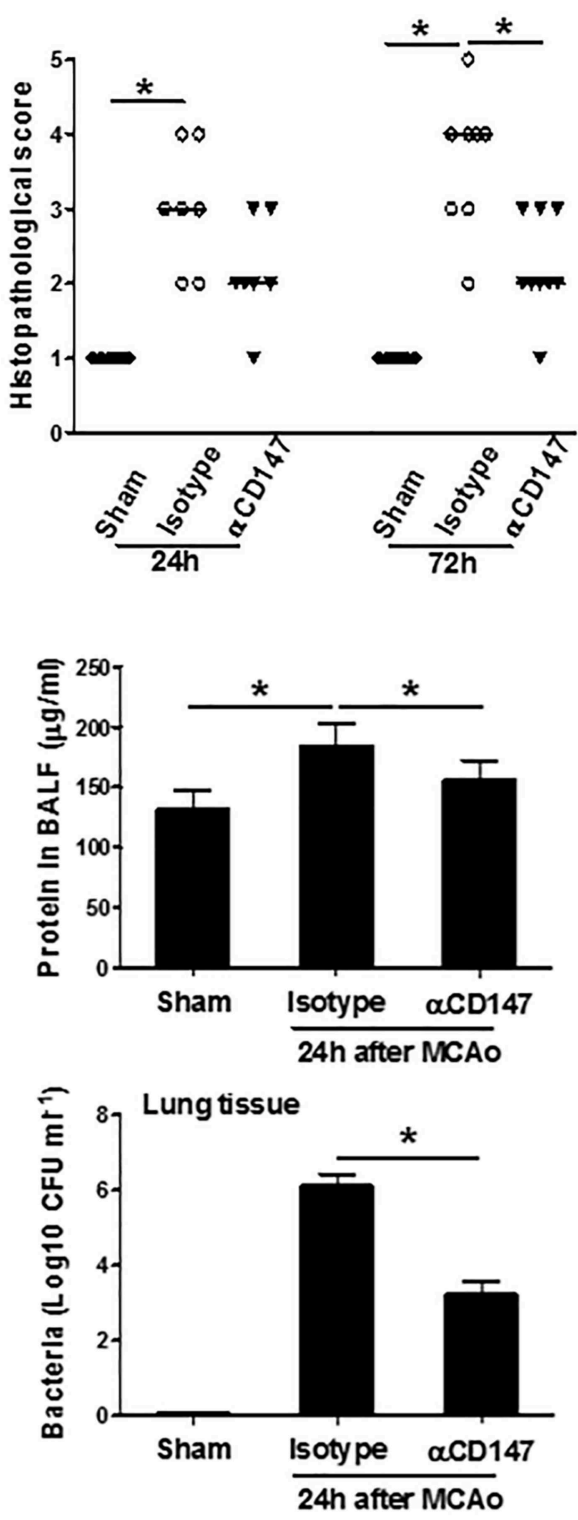

FIGURE 1 | Inhibition of CD147 attenuates post-stroke pneumonia. (A) Representative images of western blots showing CD147 protein levels in the lung tissues and semi-quantitative analysis of immunoblots. M indicates protein marker. $n=4$ per group. (B) Left panel: representative images of hematoxylin and eosin-stained lung sections. Black circles indicate the patchy areas of cellular consolidation. Arrows indicate the intra-alveolar infiltrates. Bar $=200 \mu \mathrm{m}$. Right panel: quantitative analysis of histopathological lung injury scores. Bars are median values. $n=6-9$ per group. (C) The number of cells (left panel) and levels of protein concentration (right panel) in BALF at $24 \mathrm{~h}$ after stroke. $n=6$ per group. (D) Quantitative analysis of bacterial loads by measuring colony-forming units (CFU) in BLAF (left panel) and lung tissue homogenate (right panel) cultures in indicated groups at $24 \mathrm{~h}$ after stroke. $n=6$ per group. ${ }^{*} P<0.05$. 
A
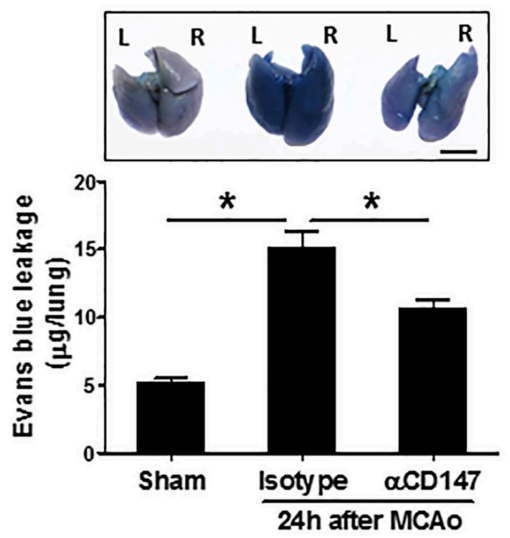

C

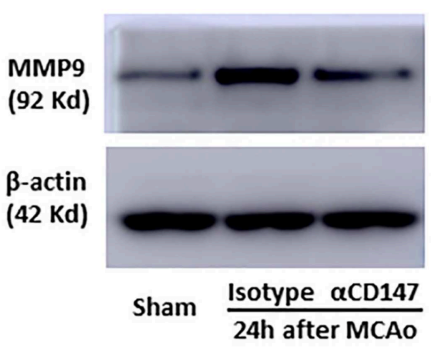

D

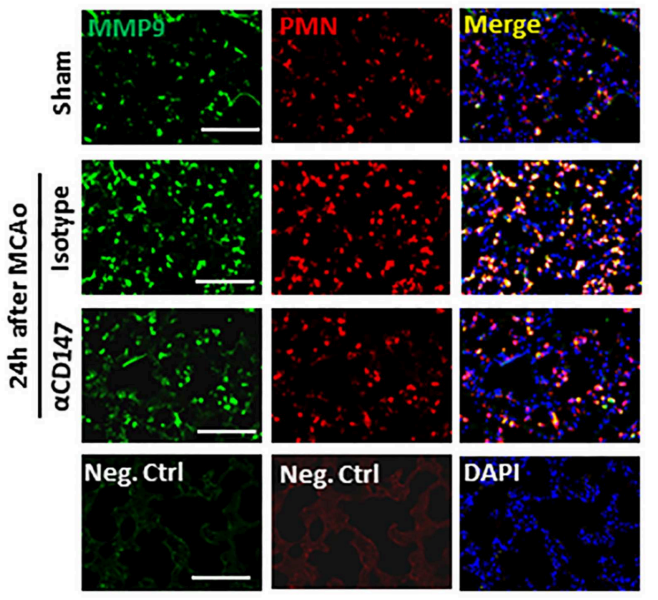

B
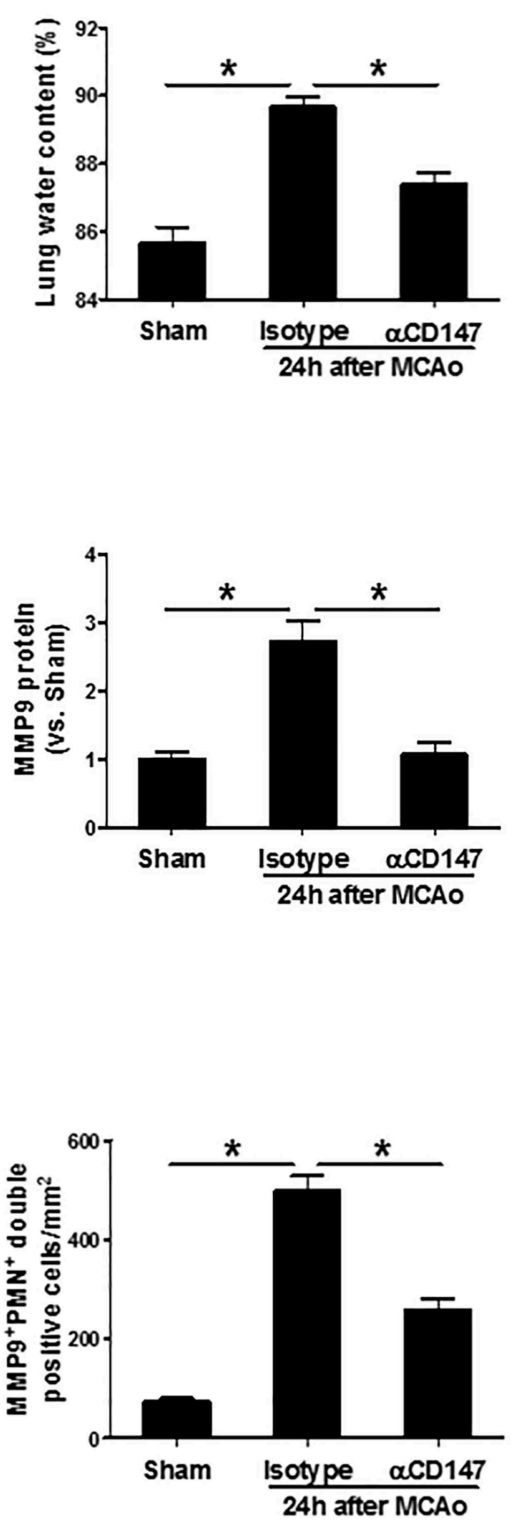

FIGURE 2 | Inhibition of CD147 attenuates post-stroke lung vascular permeability and edema through inhibition of MMP-9 activity. (A) Representative pictures and quantitative analysis of Evans blue leakage in the lung tissue at $24 \mathrm{~h}$ after stroke. L: left lung (one lobe), R: right lung (four lobe). Bar $=5 \mathrm{~mm}$. $n=6$ per group. (B) Lung water content at $24 \mathrm{~h}$ after stroke. $n=6$ per group. (C) Representative images of western blots showing MMP-9 protein levels in the lung tissues and semi-quantitative analysis of immunoblots. $n=4$ per group. (D) Double immunostaining for MMP-9 and neutrophils in the lung sections in indicated groups at $24 \mathrm{~h}$ after stroke (left panel). Neg.Ctrl indicates negative control. Bar $=100 \mu \mathrm{m}$. The number of the cells double positively stained for neutrophils and MMP-9 per mm ${ }^{2}$ was counted (right panel). $n=6-7$ per group. ${ }^{*} P<0.05$.

platelets (Figure 4A) and leukocytes (Figure 4B) at $24 \mathrm{~h}$ after stroke. Figure 4C showed the flow cytometry strategy for gating and identifying platelet aggregated leukocytes. Compared with sham mice, the circulating levels of platelet-leukocyte
$\left(\mathrm{CD} 41^{+} \mathrm{CD} 45^{+}\right), \quad$ platelet-neutrophil $\quad\left(\mathrm{CD} 41^{+} \mathrm{Ly}_{6 \mathrm{G}}{ }^{+}\right)$ and platelet-monocyte $\left(\mathrm{CD} 41^{+} \mathrm{CD} 115^{+}\right)$aggregates were significantly increased after stroke (Figure 4C). However, the increases in $\alpha$ CD147 treatment group were significantly 
lower than that in isotype treatment group (Figure 4C). ImageStream analysis was used to confirm the plateletleukocyte (neutrophil and monocyte) aggregates (Figure 4D).
In addition, the monocytes in the circulating platelet-monocyte $\left(\mathrm{CD} 41^{+} \mathrm{CD} 115^{+}\right)$aggregates were almost exclusively Ly6 $\mathrm{C}^{\mathrm{Hi}}$ cells (Figure 4E).
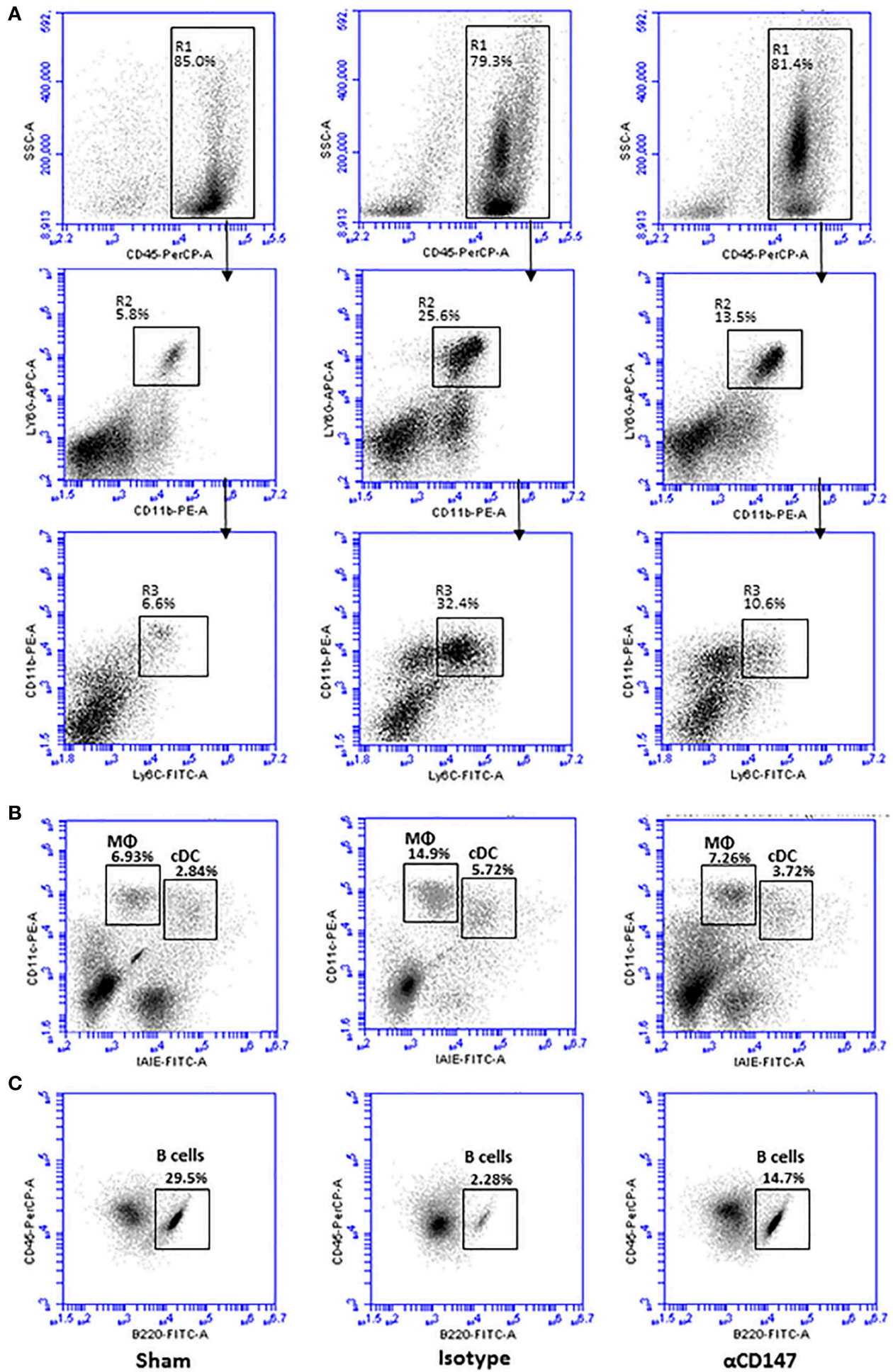

FIGURE 3 | Continued 

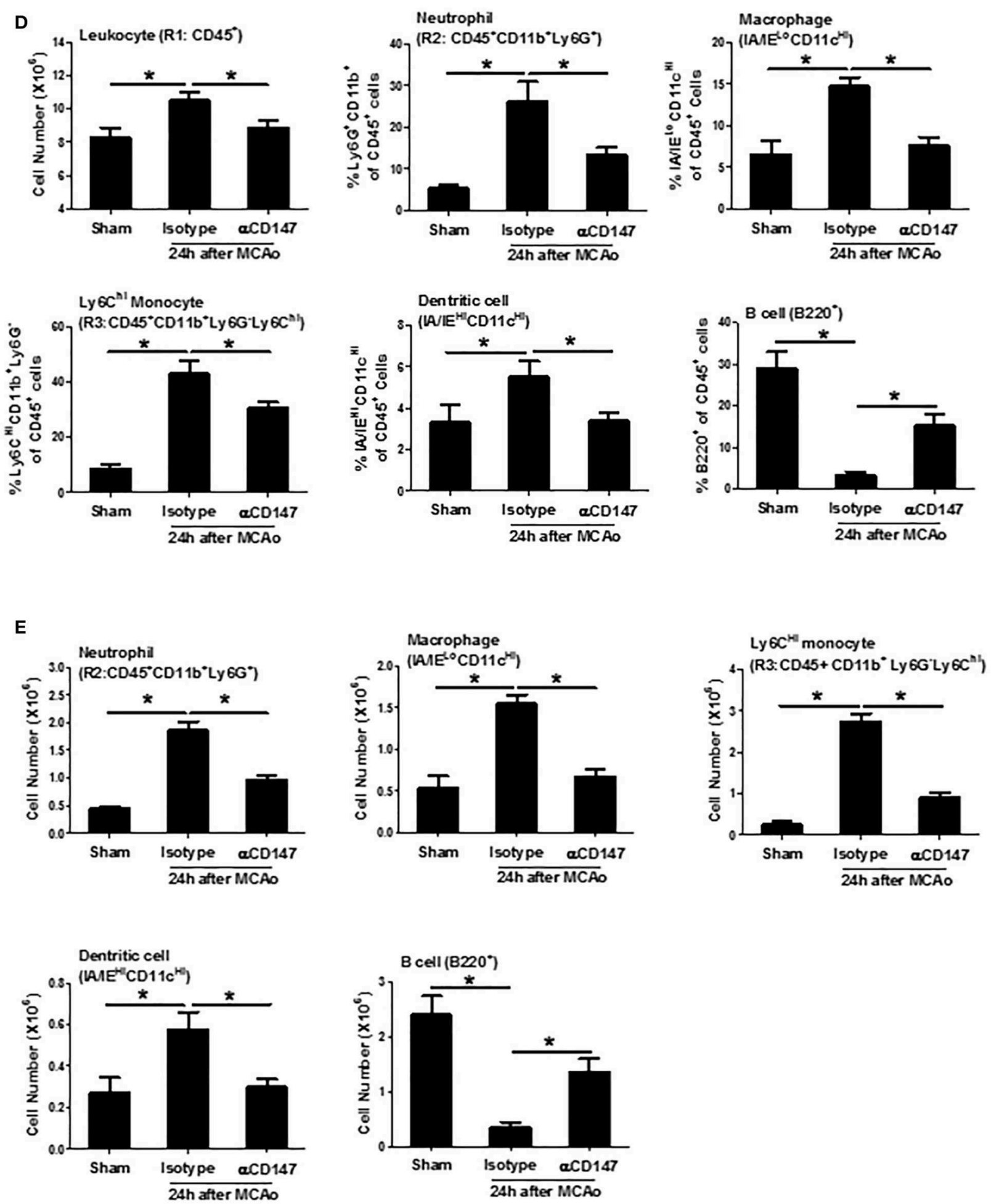

FIGURE 3 | Inhibition of CD147 modulates the changes of leukocyte subpopulations in the lung after stroke. (A) Representative flow cytometric dot plots of R1: total

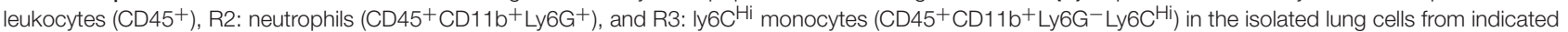
groups. Lung infiltrating cell was isolated using enzyme digestion method at $24 \mathrm{~h}$ after stroke. (B) Representative flow cytometric dot plots of lung conventional

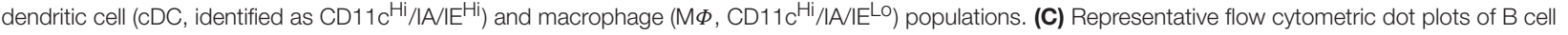
population $\left({\left.\mathrm{B} 220^{+}\right)}\right)(\mathbf{D}, \mathbf{E})$ The number and frequency of cell subpopulations in the indicated groups. $n=6$ per group. ${ }^{\star} P<0.05$. 


\section{Inhibition of CD147 Reduces Lung and Plasma IL-17A Levels After Stroke}

Interleukin 17A (IL-17A), a major inducer of the chemokines, is involved in leukocyte recruitment (31). The expression of IL-17A in the lung $\gamma \delta \mathrm{T}(\gamma \delta \mathrm{T}-17)$ cells and $\mathrm{CD}^{+} \mathrm{T}$ (Th17) cells was determined by flow cytometry. Data showed that $\alpha \mathrm{CD} 147$ treatment significantly decreased the stroke-induced upregulation of IL-17A in the lung $\gamma \delta \mathrm{T}-17$ cells (Figures 5A,B). However, its expression in $\mathrm{CD}^{+} \mathrm{T}$ cells was no significant changes between the three groups (Figures 5A,C). We also measured the concentration of IL-17A in the lung and plasma with ELISA kit. The results showed that IL-17A protein concentration was markedly increased in the lung tissue and plasma in isotype-treated mice compared with sham controls (Figures 5D,E), but they were largely attenuated in $\alpha \mathrm{CD} 147$ treated mice (Figures 5D,E). IL-17A plays a critical role in the activation and recruitment of neutrophils to the site of inflammation mainly through the induction of CXC chemokines (CXCL1 and CXCL2) $(32,33)$. Next, we examined the mRNA expression of CXCL1 and CXCL2 in the lung after stroke. The data showed that the expression of CXCL2 was significantly increased after stroke. However, it was dramatically inhibited by $\alpha \mathrm{CD} 147$ treatment (Figure 5F). The expression of CXCL1 was no significant differences between the three groups (Figure 5F).

\section{Inhibition of CD147 Increases Lung, but Not Plasma IFN- $\gamma$ Levels After Stroke}

Interferon gamma (IFN- $\gamma$ ), an important cytokine in the host defense against infection, which is derived mainly from NK and $\mathrm{CD}^{+}{ }^{+} \mathrm{T}$ cells during pneumonia (34). Next, we examined the expression of IFN- $\gamma$ in the lung NK and $\mathrm{CD}^{+}{ }^{+} \mathrm{T}$ cells after stroke. The data showed that the expression of IFN- $\gamma$ was increased both in NK1.1 ${ }^{+}$cells and CD4 ${ }^{+}$T cells in $\alpha \mathrm{CD} 147$-treated mice compared with isotype-control mice (Figures 6A-C). There was no significant changes between isotype-treated mice and sham controls (Figures 6A-C). Consistent with these findings, the results of ELISA showed that the IFN $-\gamma$ protein concentration in the lung tissue was no significant changes in isotype-treated mice at $24 \mathrm{~h}$ after stroke compared with sham controls. However, it was significantly increased in $\alpha$ CD147-treated mice (Figure 6D). The content of IFN- $\gamma$ protein in the plasma was markedly increased in isotype-treated mice compared with sham controls (Figure 6D). However, $\alpha$ CD147 treatment significantly decreased the content of IFN- $\gamma$ protein in the plasma after stroke (Figure 6E).

\section{Delayed Inhibition of CD147 Does Not Affect Stroke Injury, but Attenuates Post-stroke Lung Damage}

Infarct size is known to be associated with the incidence and severity of post stroke pneumonia $(35,36)$. Thus, we further determined whether the effects of anti-CD147 treatment on lung is independent of brain pathology, which couldn't be concluded from the above experiments with the early $\alpha$ CD147 treatment (initiated at $4 \mathrm{~h}$ after stroke onset) due to the previously shown neuroprotective effects (19). To address this issue, the mice were subjected to delayed $\alpha \mathrm{CD} 147$ treatment initiated at $8 \mathrm{~h}$ after stroke onset. This delayed treatment regimen was used because very few treatments initiated beyond $6 \mathrm{~h}$ of stroke onset could substantially reduce infarct size in acute ischemic stroke experimental models. As expected, there were no significant differences in infarct volumes and neurological deficits between isotype- and delayed $\alpha \mathrm{CD} 147$-treated groups at 3 days after stroke (Figure 7A). However, we observed a relatively higher incidence of spontaneous hemorrhagic transformation in the isotype-treated group (4 of 6 mice) than that in $\alpha \mathrm{CD} 147$ treated group ( 2 of 6 mice). Our data showed that the
A

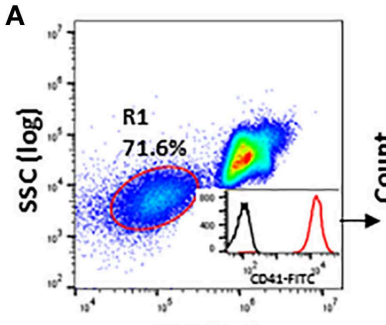

FSC (log)

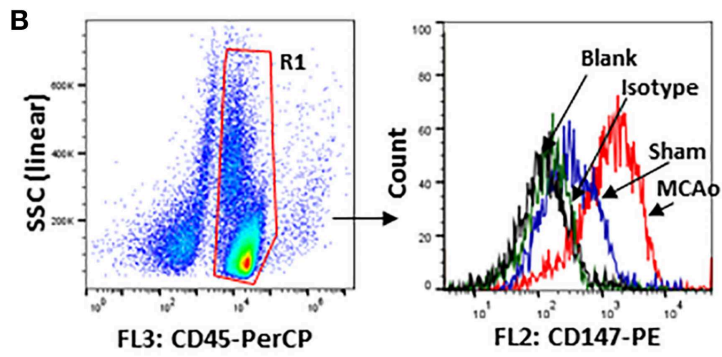

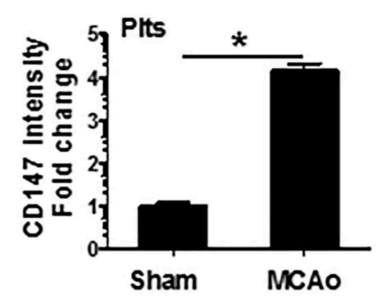

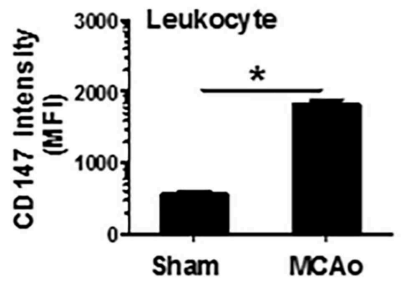

FIGURE 4 | Continued 
C
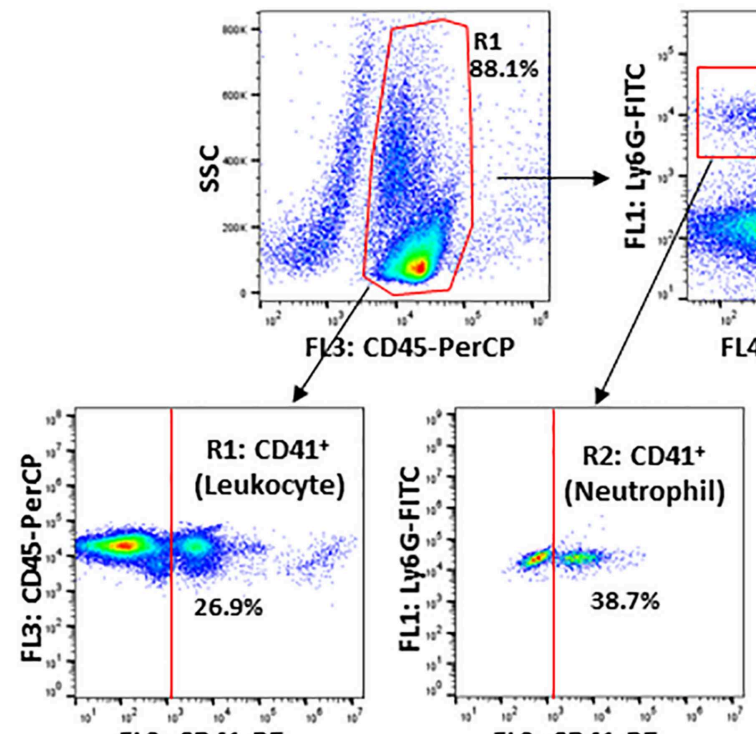

FL2: CD41-PE
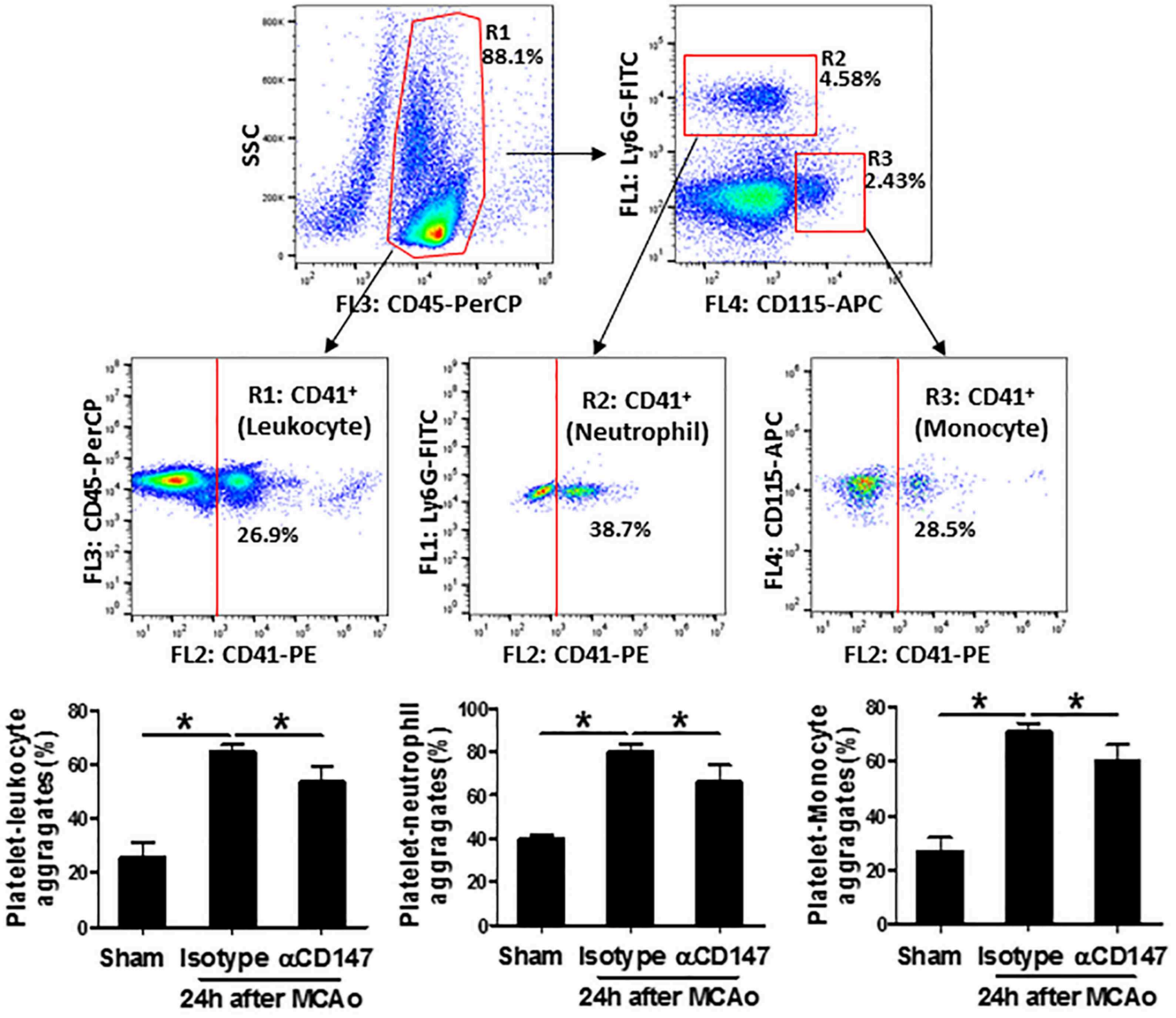

D

Neutrophil-platelet aggregates Bright field Ly6G-FITC CD41-PE

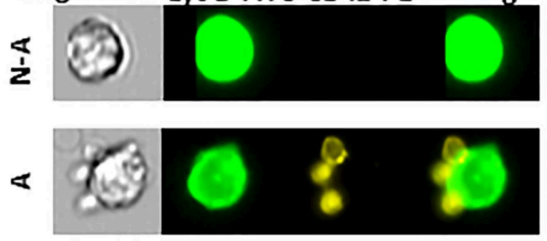

E

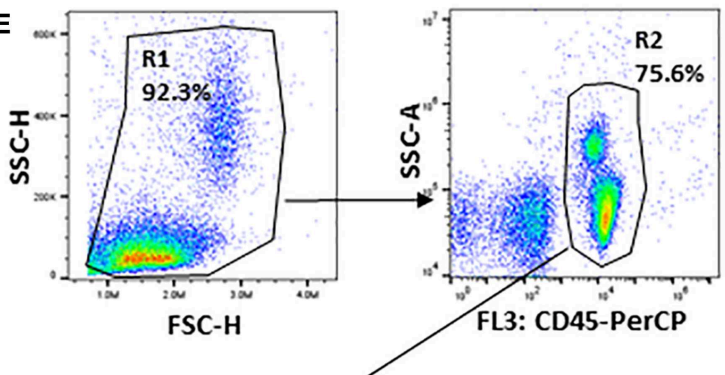

Monocyte-platelet aggregates Bright field CD115-APC CD41-PE Merge
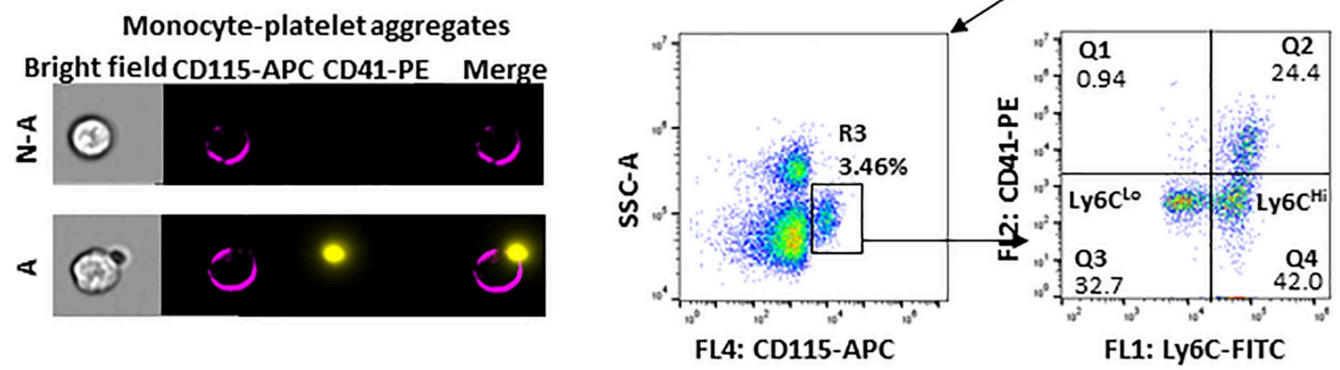

FIGURE 4 | Inhibition of CD147 decreases circulating platelet-leukocyte aggregates after stroke. (A) Representative flow cytometry strategy for gating platelet population (R1, left), which was confirmed by $>98 \%$ CD41 positive staining (insert histogram). Histogram of flow cytometry showing CD147 expression on the platelets in the indicated groups (mid) and quantitative analysis of platelets CD147 expression (right). Data are expressed as mean fluorescence intensity (MFI). $n=4$ per group. (B) Representative flow cytometry strategy for gating leukocyte population (R1: CD45+, left), histogram of flow cytometry showing CD147 expression on the leukocytes in the indicated groups (mid) and quantitative analysis of leukocytes CD147 expression (right). $n=4$ per group. (C) Representative flow cytometry 
FIGURE 4 | strategy for gating leukocyte subpopulations from the blood cells, R1: CD45+ total leukocyte, R2: neutrophil $\left(\mathrm{CD}^{+} 5^{+}\right.$ly6G $\left.{ }^{+}\right)$, R3: monocyte $\left(\mathrm{CD} 45^{+} \mathrm{CD} 115^{+}\right)$and quantitative analysis of circulating platelet-leukocyte aggregates (\% total $\mathrm{CD}_{4} 5^{+}$cells), platelet-neutrophil aggregates (\% total CD45 ${ }^{+} \mathrm{Ly} 6 \mathrm{G}^{+}$ cells) and platelet-monocyte aggregates (\% total CD $45^{+} \mathrm{CD} 115^{+}$cells) (right) in the indicated groups. $n=6$ per group. (D) Representative brightfield (BF) and fluorescent images, acquired by imageStream; Ly6G ${ }^{+}$neutrophils (green) aggregated to platelets (CD41 ${ }^{+}$yellow) (upper panel); monocyte $\left(\mathrm{CD} 115^{+}\right.$purple) aggregated to platelets (CD41+ yellow) (down panel). N-A, cell non-aggregated with platelet; A, cell aggregated with platelet. Cells are from blood sample. (E) Representative flow cytometry strategy for identifying platelet- $\mathrm{Ly} 6 \mathrm{C}^{\mathrm{LO}}$ and/or $\mathrm{Ly} 6 \mathrm{C}^{\mathrm{Hi}}$ monocyte aggregates from the blood cells. Results showed that predominant monocytes in platelet-monocyte $\left(\mathrm{CD} 41^{+} \mathrm{CD} 115^{+}\right)$aggregates were $\mathrm{Ly} 6 \mathrm{C}^{\mathrm{Hi}}$ cells.

delayed $\alpha \mathrm{CD} 147$ treatment significantly decreased post-stroke lung damage (Figure 7B) and bacterial loads in the BALF and lung tissues (Figure 7C).

\section{DISCUSSION}

The present study for the first time demonstrates that CD147 plays a critical role in post-stroke pneumonia. Antibody blockade of CD147 substantially attenuates lung susceptibility to bacterial infection and lung leukocyte infiltration and thereby ameliorates stroke-associated pneumonia (SAP) and lung histological damage after stroke.

The lungs are particularly vulnerable in patients with severe brain damage, including ischemic and hemorrhagic strokes $(37,38)$. It has been shown that ischemic stroke caused excessive leukocyte infiltration into lung and reduced alveolar macrophage phagocytic capability, which contributes importantly to poststroke lung injury (39). Innate immune cells, primarily neutrophils and monocytes, are rapidly recruited to the infected sites to control and clear invading pathogens (40). However, excessive lung leukocyte infiltration can severely compromise pulmonary function by release of various toxic factors including proteases, cationic polypeptides, proinflammatory cytokines, and reactive oxygen species (ROS). Indeed, inhibition of aberrant lung inflammatory response has been shown to protect against lung injury (41). Previous studies have demonstrated that inhibition of CD147 markedly reduces leukocyte infiltration into inflamed tissues in several mouse models, such as asthmatic lung inflammation, multiple sclerosis, autoimmune encephalomyelitis myocardial infarction and ischemic stroke $(12-14,19)$. In the present study, we demonstrated that inhibition of CD147 profoundly reduced lung local inflammatory responses following stroke, as evidenced by reduced leukocyte infiltration into lung tissue and reduced cell number and protein levels detected in the BALF. Increased circulating platelet-leukocyte aggregates represent a common mechanism for promoting leukocyte recruitment in many inflammatory diseases, including myocardial infarction, acute lung injury, and ischemic stroke (30, 42-44). In the present study, we found that CD147 expression was upregulated in circulating platelets and leukocytes after stroke, and $\alpha \mathrm{CD} 147$ treatment significantly decreased the levels of circulating platelet-leukocyte aggregates, which likely contribute to reduced lung leukocyte infiltration after stroke.

IL-17A is a major pro-inflammatory cytokine that has been shown to act as a key mediator of leukocyte recruitment (31). IL-17A can activate several signaling cascades, leading to the induction of CXC chemokines, such as Cxcl1 and Cxcl2, which in turn generate chemotactic signals for leukocyte recruitment to the site of inflammation $(31,41,45)$. Overexpression of IL$17 \mathrm{~A}$ or the administration of recombinant IL-17A in the lung promotes the production and release of CXC chemokines and neutrophil recruitment (46). In contrast, selective inhibition of IL-17A signaling reduces ischemia/reperfusion-induced brain damage in mice (47-49). $\gamma \delta \mathrm{T}$ cells and $\mathrm{CD} 4{ }^{+} \mathrm{Th} 17 \mathrm{~T}$ cells, both are enriched in the lung tissue, are considered to be the major cellular source of IL-17A $(31,50)$. In the present study, we found that the expression of IL-17A was increased at $24 \mathrm{~h}$ in the lung tissue after stroke, which was mainly derived from $\gamma \delta \mathrm{T}$ cells, but not from $\mathrm{CD} 4^{+}$Th17 cells. More importantly, we found that the increased IL-17A-expressing $\gamma \delta \mathrm{T}$ cells, as well as the increased IL-17A protein levels in both lung tissue and plasma after stroke, were significantly reduced in the $\alpha \mathrm{CD} 147$-treated group compared with the isotype-treated group. In mice, $\gamma \delta \mathrm{T}$ cells can be characterized by the expression of CCR6 and either $\mathrm{V} \gamma 1, \mathrm{~V} \gamma 4$, or $\mathrm{V} \gamma 6$. It has been shown that $\mathrm{V} 6^{+} / \mathrm{CCR}^{+} \gamma \delta \mathrm{T}$ cells are the major producer of IL-17A in the ischemic brain (51). Which subsets of $\gamma \delta \mathrm{T}$ cells are the main producer of IL-17A in the lung after stroke and its potential modulation by CD147 warrant further investigation.

IFN- $\gamma$ is a pivotal mediator in host defense against a variety of infectious agents. It is produced mainly by NK cells and antigenactivated $\mathrm{T}$ cells. It has been shown that an impaired early NKand T-cell response, particularly reduced IFN- $\gamma$ production, is critical for stroke-induced defect of the antibacterial defense (5). Adoptive transfer of IFN- $\gamma$-producing NK and T cells or early treatment with recombinant IFN- $\gamma$ inhibited bacteremia and pneumonia $(5,31)$. However, IFN- $\gamma$ may act as a doubleedged sword in the pathophysiology of stroke. Although IFN- $\gamma$ helps to protect against bacterial infection and to prevent the stroke-associated pneumonia, elevated levels of IFN- $\gamma$ in the circulation also could exacerbate ischemic brain injury through enhancing systemic inflammation (52). It has been reported that antibody blockade of CD147 stimulated IFN $-\gamma$ production in the $\mathrm{CD} 3 / \mathrm{CD} 28$ antibodies-activated human T cells (16). In the present study, we found that $\alpha \mathrm{CD} 147$ treatment had dual beneficial effects, i.e., it increased the IFN- $\gamma$ levels in the lung tissue that are mainly derived from $\mathrm{NK}_{1} .1^{+}$cells and $\mathrm{CD} 4^{+} \mathrm{T}$ cells, whereas reduced the IFN- $\gamma$ levels in the circulating plasma. The mechanisms by which $\alpha \mathrm{CD} 147$ treatment differentially alters the IFN- $\gamma$ in the lung and blood remain unknown and warrant further investigation.

Stroke size is associated with the incidence and severity of SAP $(35,36)$. Our previous study has shown that inhibition of CD147 significantly reduced stroke size (19). This raises an important question whether the protection against SAP by $\alpha \mathrm{CD} 147$ treatment is simply a result of smaller stroke size. To address this issue, the mice were subjected to $\alpha \mathrm{CD} 147$ treatment 

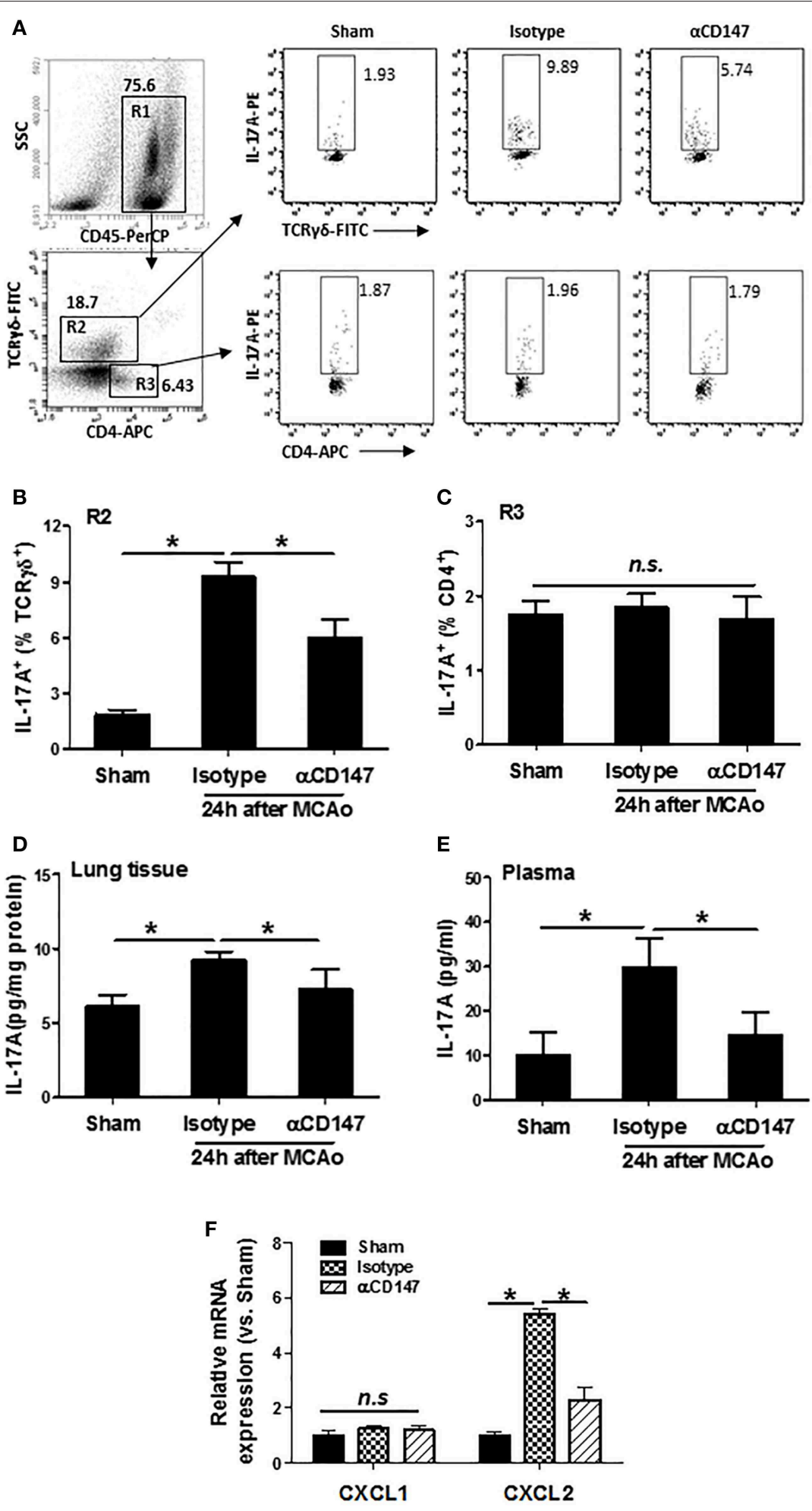

FIGURE 5 | Inhibition of CD147 reduces lung and plasma IL-17A expression after stroke. (A) Representative flow cytometry strategy for gating and identifying

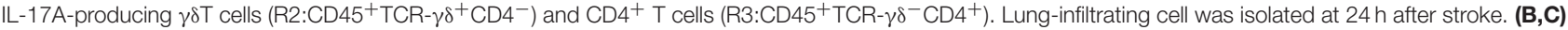
Quantification of lung IL-17A-producing $\gamma \delta$ T cells (B) and CD4 + T cells (C) in the indicated groups. $n=6$ per group. (D,E) ELISA assay of IL-17A protein concentrations in the lung tissue (D) and plasma (E) at $24 \mathrm{~h}$ after stroke. $n=6$ per group. $n$.s. indicates not statistically significant. ${ }^{\star} P<0.05$. (F) Real-time RT-PCR analysis of mRNA expression of the chemokines (CXCL1 and CXCL2) in the lung after stroke. $n=5$ per group. n.s. indicates not statistically significant. ${ }^{\star} P<0.05$. 

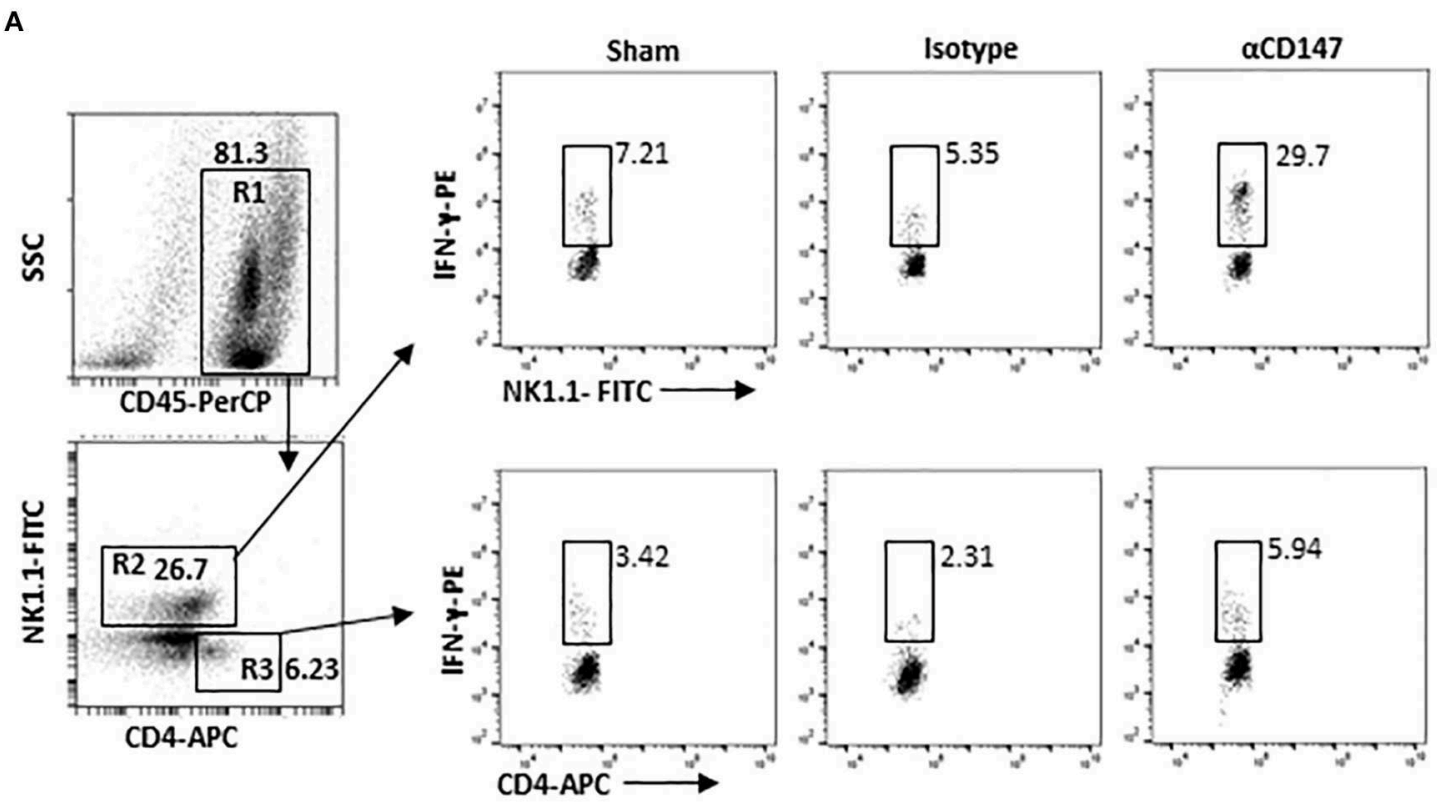

B

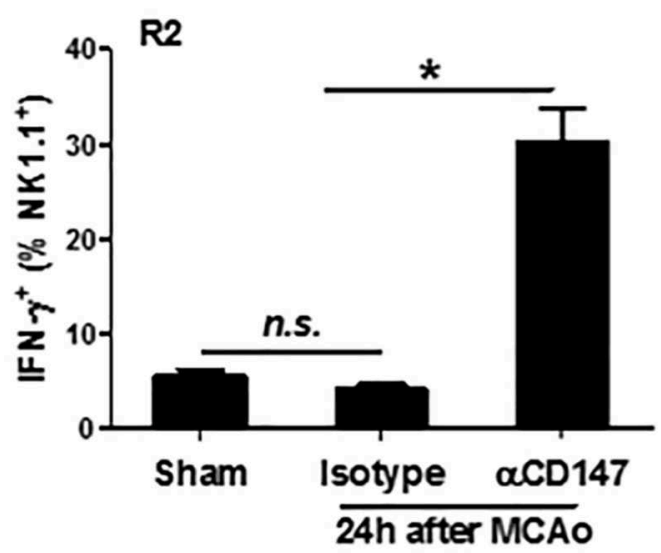

C

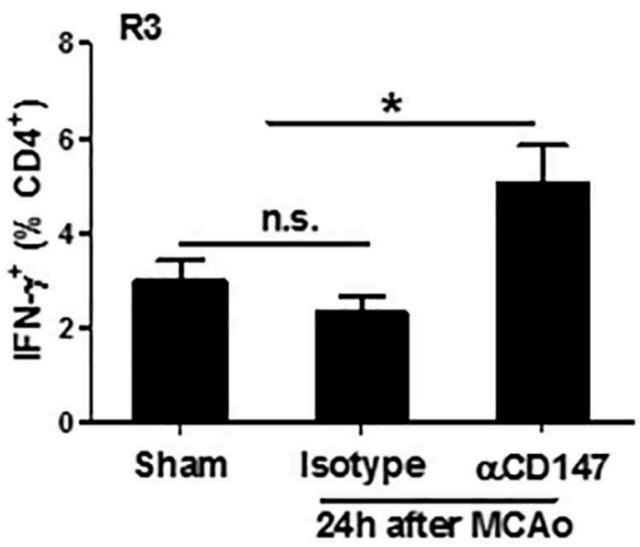

D

E
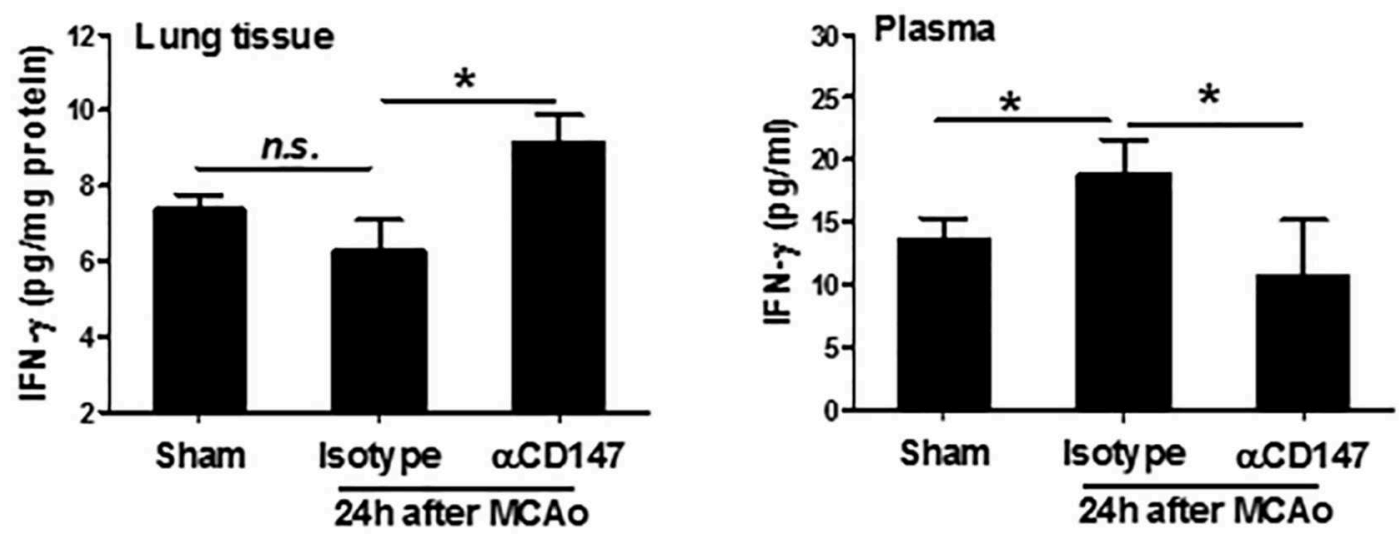

FIGURE 6 | Inhibition of CD147 increases lung, but not plasma IFN- $\gamma$ expression after stroke. (A) Representative flow cytometry strategy for gating and identifying IFN- $\gamma$-producing NK1.1 cells (R2: CD45 $\left.{ }^{+} \mathrm{NK} 1.1^{+} \mathrm{CD} 4^{-}\right)$and $\mathrm{CD} 4^{+} \mathrm{T}$ cells $\left(\mathrm{R} 3\right.$ : CD45 $\left.{ }^{+} \mathrm{NK} 1.1^{-} \mathrm{CD} 4^{+}\right)$. Lung infiltrating-cell was isolated at $24 \mathrm{~h}$ after stroke. (B,C) Quantification of lung IFN- $\gamma$-producing NK1.1 $1^{+}$cells (B) and CD4 ${ }^{+}$T cells (C) in the indicated groups. $n=6$ per group. (D,E) ELISA assay of IFN- $\gamma$ protein concentration in the lung tissue (D) and plasma (E) at $24 \mathrm{~h}$ after stroke. $n=6$ per group. n.s. indicates not statistically significant. ${ }^{*} P<0.05$. 
A

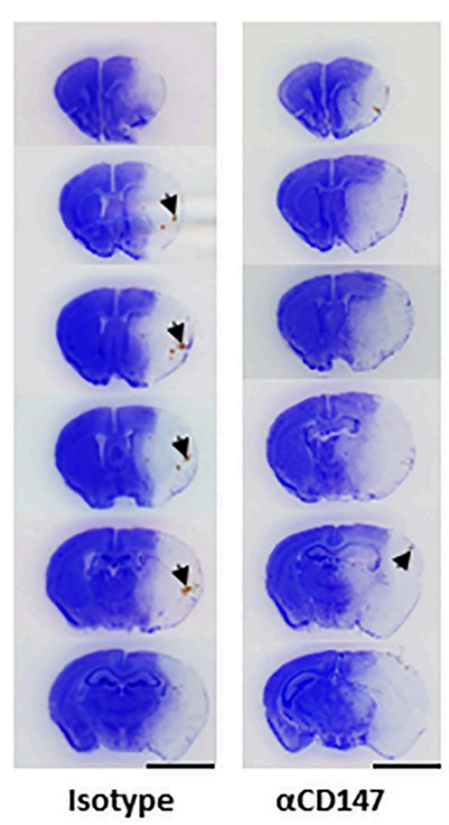

B

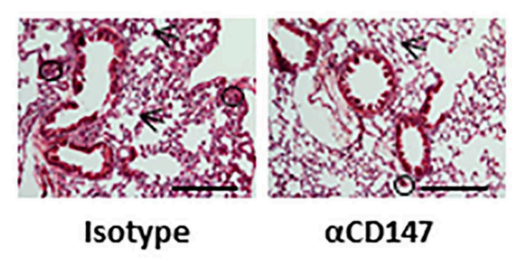

C

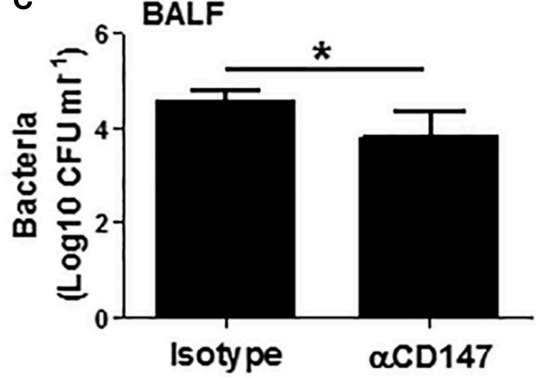

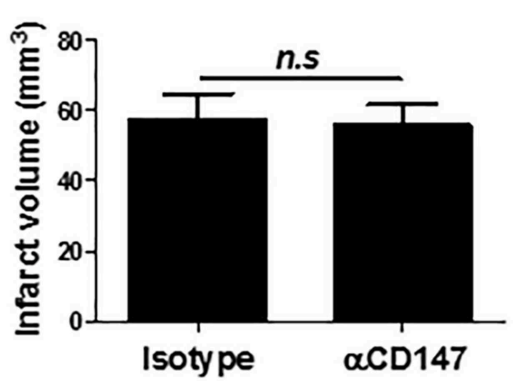
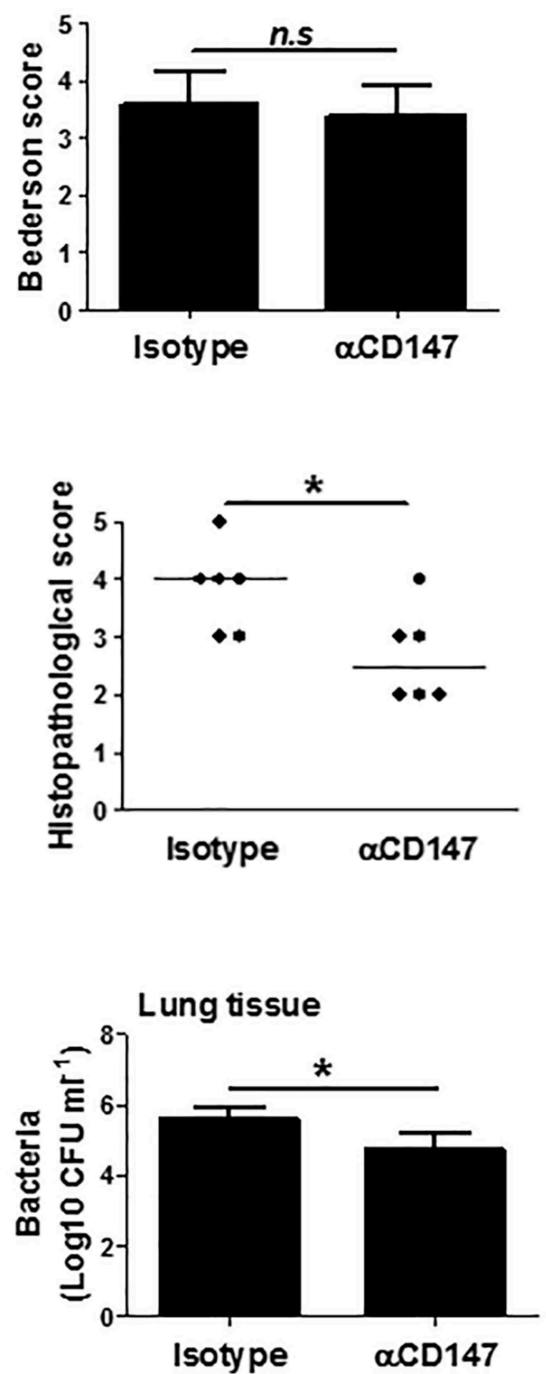

FIGURE 7 | Delayed inhibition of CD147 does not affect brain injury, but attenuates post-stroke lung damage. (A) Representative images of cresyl violet-stained brain coronal sections of mice (left panel). Blue color: intact tissues, white color: infarct tissues. Arrows indicate spontaneous hemorrhagic transformation. Bar $=5 \mathrm{~mm}$. Infarct volume and Neurological deficits (Right panel). $n=6$ per group, n.s. indicates not statistically significant. (B) Representative images of hematoxylin and eosin-stained lung sections (Left panel). Black circles indicate the patchy areas of cellular consolidation. Arrows indicate the intra-alveolar infiltrates. Bar $=200 \mu \mathrm{m}$. Quantitative analysis of histopathological lung injury scores (Right panel). Bars are median values. $n=6$ per group. (C) Quantitative analysis of bacterial loads by measuring colony-forming units (CFU) in BLAF (left panel) and lung tissue homogenate (right panel) cultures in indicated groups at 3 days after stroke. $n=6$ per group. ${ }^{*} P<0.05$.

initiated at $8 \mathrm{~h}$ after stroke onset. We found that the delayed aCD147 treatment did not alter stroke size compared with the isotype-treated control, but was still effective in reducing bacterial loads and lung tissue damage at 3 days after stroke. These findings suggest that $\alpha$ CD 147 treatment attenuates SAP via mechanisms that are likely independent of the stroke size. 


\section{CONCLUSIONS}

The present study demonstrates that inhibition of CD147 ameliorates SAP through inhibiting aberrant lung immune response and bacterial infection after stroke. Thus, CD147 might represent a novel and promising target for preventing/treating SAP.

\section{DATA AVAILABILITY}

All datasets generated for this study are included in the manuscript and/or the Supplementary Files.

\section{ETHICS STATEMENT}

All animal experiments were approved by the Institutional Animal Care and Use Committee at Penn State University College of Medicine.

\section{REFERENCES}

1. Westendorp WF, Nederkoorn PJ, Vermeij JD, Dijkgraaf MG, van de Beek D. Post-stroke infection: a systematic review and meta-analysis. BMC Neurol. (2011) 11:110. doi: 10.1186/1471-2377-11-110

2. Meisel C, Schwab JM, Prass K, Meisel A, Dirnagl U. Central nervous system injury-induced immune deficiency syndrome. Nat Rev Neurosci. (2005) 6:775-86. doi: 10.1038/nrn1765

3. Shi K, Wood K, Shi FD, Wang X, Liu Q. Stroke-induced immunosuppression and poststroke infection. Stroke Vasc Neurol. (2018) 3:34-41. doi: 10.1136/svn-2017-000123

4. Meisel C, Prass K, Braun J, Victorov I, Wolf T, Megow D, et al. Preventive antibacterial treatment improves the general medical and neurological outcome in a mouse model of stroke. Stroke. (2004) 35:2-6. doi: 10.1161/01.STR.0000109041.899 59.4C

5. Prass K, Meisel C, Höflich C, Braun J, Halle E, Wolf T, et al. Strokeinduced immunodeficiency promotes spontaneous bacterial infections and is mediated by sympathetic activation reversal by poststroke $\mathrm{T}$ helper cell type 1-like immunostimulation. J Exp Med. (2003) 198:72536. doi: 10.1084/jem.20021098

6. Wong CH, Jenne CN, Lee WY, Léger C, Kubes P. Functional innervation of hepatic iNKT cells is immunosuppressive following stroke. Science. (2011) 334:101-5. doi: 10.1126/science. 1210301

7. Kalra L, Irshad S, Hodsoll J, Simpson M, Gulliford M, Smithard D, et al. Prophylactic antibiotics after acute stroke for reducing pneumonia in patients with dysphagia (STROKE-INF): a prospective, cluster-randomised, openlabel, masked endpoint, controlled clinical trial. Lancet. (2015) 386:183544. doi: 10.1016/S0140-6736(15)00126-9

8. Westendorp WF, Vermeij JD, Zock E, Hooijenga IJ, Kruyt ND, Bosboom HJ, et al. The preventive antibiotics in stroke study (PASS): a pragmatic randomised open-label masked endpoint clinical trial. Lancet. (2015) 385:1519-26. doi: 10.1016/S0140-6736(14)62456-9

9. Maier IL, Karch A, Mikolajczyk R, Bähr M, Liman J. Effect of beta-blocker therapy on the risk of infections and death after acute stroke-a historical cohort study. PLoS ONE. (2015) 10:e0116836. doi: 10.1371/journal.pone.0116836

10. Wang C, Jin $\mathrm{R}$, Zhu $\mathrm{X}$, Yan J, Li G. Function of CD147 in atherosclerosis and atherothrombosis. J Cardiovasc Transl Res. (2015) 8:59-66. doi: 10.1007/s12265-015-9608-6

11. Damsker JM, Okwumabua I, Pushkarsky T, Arora K, Bukrinsky MI, Constant SL. Targeting the chemotactic function of CD147 reduces collagen-induced arthritis. Immunology. (2009) 126:5562. doi: 10.1111/j.1365-2567.2008.02877.x

\section{AUTHOR CONTRIBUTIONS}

RJ, SL, MW, and WZ performed the experiments and the data analysis. RJ and GL designed and supervised the study. RJ wrote the manuscript. GL revised the manuscript.

\section{FUNDING}

This work was supported by National Institutes of Health grants NS088719 and NS089991 (GL).

\section{SUPPLEMENTARY MATERIAL}

The Supplementary Material for this article can be found online at: https://www.frontiersin.org/articles/10.3389/fneur. 2019.00853/full\#supplementary-material

12. Gwinn WM, Damsker JM, Falahati R, Okwumabua I, Kelly-Welch A, Keegan $\mathrm{AD}$, et al. Novel approach to inhibit asthma-mediated lung inflammation using anti-CD147 intervention. J Immunol. (2006) 177:48709. doi: 10.4049/jimmunol.177.7.4870

13. Seizer P, Ochmann C, Schönberger T, Zach S, Rose M, Borst $O$, et al. Disrupting the EMMPRIN (CD147)-cyclophilin A interaction reduces infarct size and preserves systolic function after myocardial ischemia and reperfusion. Arterioscler Thromb Vasc Biol. (2011) 31:137786. doi: 10.1161/ATVBAHA.111.225771

14. Agrawal SM, Silva C, Tourtellotte WW, Yong VW. EMMPRIN: a novel regulator of leukocyte transmigration into the CNS in multiple sclerosis and experimental autoimmune encephalomyelitis. J Neurosci. (2011) 31:66977. doi: 10.1523/JNEUROSCI.3659-10.2011

15. Bernard SC, Simpson N, Join-Lambert O, Federici C, Laran-Chich MP, Maïssa N, et al. Pathogenic Neisseria meningitidis utilizes CD147 for vascular colonization. Nat Med. (2014) 20:725-31. doi: 10.1038/nm.3563

16. Hu J, Dang N, Yao H, Li Y, Zhang H, Yang X, et al. Involvement of HAb18G/CD147 in T cell activation and immunological synapse formation. J Cell Mol Med. (2010) 14:2132-43. doi: 10.1111/j.1582-4934.2010.01012.x

17. Ruiz S, Castro-Castro A, Bustelo XR. CD147 inhibits the nuclear factor of activated T-cells by impairing Vav1 and Rac1 downstream signaling. J Biol Chem. (2008) 283:5554-66. doi: 10.1074/jbc.M708566200

18. Yang H, Wang J, Li Y, Yin ZJ, Lv TT, Zhu P, et al. CD147 modulates the differentiation of T-helper 17 cells in patients with rheumatoid arthritis. APMIS. (2017) 125:24-31. doi: 10.1111/apm.12629

19. Jin R, Xiao AY, Chen R, Granger DN, Li G. Inhibition of CD147 (Cluster of differentiation 147) ameliorates acute ischemic stroke in mice by reducing thromboinflammation. Stroke. (2017) 48:3356-65. doi: 10.1161/STROKEAHA.117.018839

20. Jin R, Zhu X, Liu L, Nanda A, Granger DN, Li G. Simvastatin attenuates stroke-induced splenic atrophy and lung susceptibility to spontaneous bacterial infection in mice. Stroke. (2013) 44:1135-43. doi: 10.1161/STROKEAHA.111.000633

21. Bederson JB, Pitts LH, Tsuji M, Nishimura MC, Davis RL, Bartkowski H. Rat middle cerebral artery occlusion: evaluation of the model and development of a neurologic examination. Stroke. (1986) 17:4726. doi: 10.1161/01.STR.17.3.472

22. Koma T, Yoshimatsu K, Nagata N, Sato Y, Shimizu K, Yasuda SP, et al. Neutrophil depletion suppresses pulmonary vascular hyperpermeability and occurrence of pulmonary edema caused by hantavirus infection in C.B-17 SCID mice. J Virol. (2014) 88:7178-88. doi: 10.1128/JVI.00254-14

23. Stanley D, Mason LJ, Mackin KE, Srikhanta YN, Lyras D, Prakash MD, et al. Translocation and dissemination of commensal bacteria in post-stroke infection. Nat Med. (2016) 22:1277-84. doi: 10.1038/nm.4194 
24. D’Alessio FR, Tsushima K, Aggarwal NR, West EE, Willett MH, Britos MF, et al. CD4+CD25+Foxp3+ Tregs resolve experimental lung injury in mice and are present in humans with acute lung injury. J Clin Invest. (2009) 119:2898-913. doi: 10.1172/JCI36498

25. Baral P, Umans BD, Li L, Wallrapp A, Bist M, Kirschbaum T, et al. Nociceptor sensory neurons suppress neutrophil and $\gamma \delta \mathrm{T}$ cell responses in bacterial lung infections and lethal pneumonia. Nat Med. (2018) 24:41726. doi: 10.1038/nm.4501

26. Bai Y, Huang W, Ma LT, Jiang JL, Chen ZN. Importance of N-glycosylation on CD147 for its biological functions. Int J Mol Sci. (2014) 15:635677. doi: 10.3390/ijms15046356

27. Schulte-Herbrüggen O, Klehmet J, Quarcoo D, Meisel C, Meisel A. Mouse strains differ in their susceptibility to poststroke infections. Neuroimmunomodulation. (2006) 13:13-8. doi: 10.1159/000092109

28. Grommes J, Soehnlein O. Contribution of neutrophils to acute lung injury. Mol Med. (2011) 17:293-307. doi: 10.2119/molmed.2010.00138

29. Weber GF, Chousterman BG, Hilgendorf I, Robbins CS, Theurl I, Gerhardt LM, et al. Pleural innate response activator B cells protect against pneumonia via a GM-CSF-IgM axis. J Exp Med. (2014) 211:124356. doi: 10.1084/jem.20131471

30. Finsterbusch M, Schrottmaier WC, Kral-Pointner JB, Salzmann M, Assinger A. Measuring and interpreting platelet-leukocyte aggregates. Platelets. (2018) 29:677-85. doi: 10.1080/09537104.2018.14 30358

31. Papotto PH, Ribot JC, Silva-Santos B. IL-17+ $\gamma \delta \mathrm{T}$ cells as kick-starters of inflammation. Nat Immunol. (2017) 18:604-11. doi: 10.1038/ni.3726

32. Brackett CM, Muhitch JB, Evans SS, Gollnick SO. IL-17 promotes neutrophil entry into tumor-draining lymph nodes following induction of sterile inflammation. J Immunol. (2013) 191:4348-57. doi: 10.4049/jimmunol.1103621

33. Valeri M, Raffatellu M. Cytokines IL-17 and IL-22 in the host response to infection. Pathog Dis. (2016) 74:ftw111. doi: 10.1093/femspd/ftw111

34. Schoenborn JR, Wilson CB. Regulation of interferon- $\gamma$ during innate and adaptive immune responses. Adv Immunol. (2007) 96:41-101. doi: 10.1016/S0065-2776(07)96002-2

35. Matz K, Seyfang L, Dachenhausen A, Teuschl Y, Tuomilehto J, Brainin $\mathrm{M}$, et al. Post-stroke pneumonia at the stroke unit-a registry based analysis of contributing and protective factors. BMC Neurol. (2016) 16:107. doi: 10.1186/s12883-016-0627-y

36. Liesz A, Hagmann S, Zschoche C, Adamek J, Zhou W, Sun L, et al. The spectrum of systemic immune alterations after murine focal ischemia: immunodepression versus immunomodulation. Stroke. (2009) 40:284958. doi: 10.1161/STROKEAHA.109.549618

37. Bai W, Li W, Ning YL, Li P, Zhao Y, et al. Blood glutamate levels are closely related to acute lung injury and prognosis after stroke. Front Neurol. (2018) 8:755. doi: 10.3389/fneur.2017.00755

38. Elmer J, Hou P, Wilcox SR, Chang Y, Schreiber H, et al. Acute respiratory distress syndrome after spontaneous intracerebral hemorrhage. Crit Care Med. (2013) 41:1992-2001. doi: 10.1097/CCM.0b013e31828 a3f $4 \mathrm{~d}$

39. Samary CS, Ramos AB, Maia LA, Rocha NN, Santos CL, Magalhães $\mathrm{RF}$, et al. Focal ischemic stroke leads to lung injury and reduces alveolar macrophage phagocytic capability in rats. Crit Care. (2018) 22:249. doi: 10.1186/s13054-018-2164-0

40. Casson CN, Doerner JL, Copenhaver AM, Ramirez J, Holmgren AM, Boyer MA, et al. Neutrophils and Ly6Chi monocytes collaborate in generating an optimal cytokine response that protects against pulmonary Legionella pneumophila infection. PLoS Pathog. (2017) 13:e1006309. doi: 10.1371/journal.ppat.1006309

41. Righetti RF, Dos Santos TM, Camargo LDN, Aristóteles LRCRB, Fukuzaki S, de Souza FCR, et al. Protective effects of anti-IL17 on acute lung injury induced by LPS in mice. Front Pharmacol. (2018) 9:1021. doi: 10.3389/fphar.2018.01021

42. Ott I, Neumann FJ, Kenngott S, Gawaz M, Schomig A. Procoagulant inflammatory responses of monocytes after direct balloon angioplasty in acute myocardial infarction. Am J Cardiol. (1998) 82:938-42. doi: 10.1016/S0002-9149(98)00509-8

43. Zarbock A, Ley K. The role of platelets in acute lung injury (ALI). Front Biosci. (2009) 14:150-8. doi: 10.2741/3236

44. Schmalbach B, Stepanow O, Jochens A, Riedel C, Deuschl G, Kuhlenbäumer G. Determinants of platelet-leukocyte aggregation and platelet activation in stroke. Cerebrovasc Dis. (2015) 39:176-80. doi: 10.1159/000375396

45. Miossec P. Update on interleukin-17: a role in the pathogenesis of inflammatory arthritis and implication for clinical practice. RMD Open. (2017) 3:e0002. doi: 10.1136/rmdopen-2016-000284

46. Laan M, Cui ZH, Hoshino H, Lotvall J, Sjostrand M, Gruenert DC, et al. Neutrophil recruitment by human IL-17 via C-X-C chemokine release in the airways. J Immunol. (1999) 162:2347-52.

47. Shichita T, Sugiyama Y, Ooboshi H, Sugimori H, Nakagawa R, Takada I, et al. Pivotal role of cerebral interleukin-17-producing gammadeltaT cells in the delayed phase of ischemic brain injury. Nat Med. (2009) 15:94650. doi: 10.1038/nm.1999

48. Gelderblom M, Weymar A, Bernreuther C, Velden J, Arunachalam P, Steinbach K, et al. Neutralization of the IL-17 axis diminishes neutrophil invasion and protects from ischemic stroke. Blood. (2012) 120:3793802. doi: 10.1182/blood-2012-02-412726

49. Gelderblom M, Gallizioli M, Ludewig P, Thom V, Arunachalam P, Rissiek B, et al. IL-23 (interleukin-23)-producing conventional dendritic cells control the detrimental IL-17(interleukin-17) response in stroke. Stroke. (2018) 49:155-64. doi: 10.1161/STROKEAHA.117.019101

50. Cheng $\mathrm{M}, \mathrm{Hu}$ S. Lung-resident $\gamma \delta \mathrm{T}$ cells and their roles in lung diseases. Immunology. (2017) 151:375-84. doi: 10.1111/imm.12764

51. Arunachalam P, Ludewig P, Melich P, Arumugam TV, Gerloff C, Prinz I, et al. CCR6 (CC chemokine receptor 6) is essential for the migration of detrimental natural interleukin-17-producing $\gamma \delta \mathrm{T}$ cells in stroke. Stroke. (2017) 48:1957-65. doi: 10.1161/STROKEAHA.117.016753

52. Seifert HA, Collier LA, Chapman CB, Benkovic SA, Willing AE, Pennypacker KR. Pro-inflammatory interferon gamma signaling is directly associated with stroke induced neurodegeneration. J Neuroimmune Pharmacol. (2014) 9:67989. doi: 10.1007/s11481-014-9560-2

Conflict of Interest Statement: The authors declare that the research was conducted in the absence of any commercial or financial relationships that could be construed as a potential conflict of interest.

Copyright (c) 2019 Jin, Liu, Wang, Zhong and Li. This is an open-access article distributed under the terms of the Creative Commons Attribution License (CC BY). The use, distribution or reproduction in other forums is permitted, provided the original author(s) and the copyright owner(s) are credited and that the original publication in this journal is cited, in accordance with accepted academic practice. No use, distribution or reproduction is permitted which does not comply with these terms. 